\title{
The existentialist view (on the content of experience) defended
}

\author{
Roberto Horácio de Sá Pereira \\ robertohsp@gmail.com \\ Universidade Federal do Rio de Janeiro, Rio de Janeiro, RJ, Brasil
}

resumo Este artigo apresenta um objetivo duplo: considerar detalhadamente as objeções contra a concepção existencialista do conteúdo da experiência visual e desenvolver e defender uma versão dela que evite tais objeções, solucionando, especificamente, o dito "problema da particularidade". A tese principal é de que o conteúdo existencial da experiência visual deve ser compreendido como relativizado, sendo conteúdo incompleto (em vez de um clássico, de proposições completas), modelado como uma função do sêxtuplo do objeto, agente, tempo, lugar, relação causal, e mundo para valores absolutos.

palavras-chave Conteúdo existencial da percepção; conteúdo relativizado; problema da particularidade.

\section{Introduction}

It used to be a common ground that the content of visual experience involves the very properties things appear to have, but do not involve the very objects that appear to have them. This content is said to be an existentially quantified proposition, which would naturally be expressed by saying something of the form, "There is a yellow cube straight ahead." One reason sometimes given in support of the existentialist view is that the object does not seem to contribute to the phenomenology of experience. Experiences with the same phenomenal character can represent the world in the same way, even if they are experiences of numerically different objects. Another reason sometimes given in favor of the exis- 


\section{4}

tentialist view is that experiences can represent the world as being the same way, even if an experience is a hallucination in which no object is perceived at all.

The existentialist view figures prominently in the work of thinkers as different as Lewis (1980), McGinn (1982), Searle (1983), Millar (1relativized 991), and Davies (1992). However, in the last decade, the existentialist view on the content of visual experience has been questioned on several grounds. Soteriou (2000) claims that one must reject the existentialist view if one rejects the assumption that visual experiences represent a causal relation between an object and the experience itself and if one accepts the natural assumption-what he calls Searle's assumption- that the question of veridicality of experience cannot be settled independently of the question of whether an object is being perceived.

Tye, on the other hand, claims that the existentialist view "lacks a clear motivation" (2009, p. 79). Furthermore, he rejects not only the assumption that visual experiences represent a causal relation between an object and the experience itself, but also Searle's assumption. According to Tye, the existentialist view must be rejected because "it yields an unequivocal result of veridicality in certain cases in which such a result is not warranted" (2009, p. 79).

The crucial difficulty of the existentialist view can be traced back to what Searle in the eighties called the particularity problem. As we saw, one of the reasons motivating the existentialist view is that the object does not seem to contribute to the phenomenology of experience. Experiences with the same phenomenology can represent the world in the same way, even if they are experiences of numerically different objects. According to Searle, however, "we have intentional contents with particular and not general conditions of satisfaction" (SEARLE, 1983, p. 63). Thus, the condition of satisfaction in a visual experience of a yellow cube straight ahead requires the presence of the yellow cube straight ahead and not the presence of any qualitatively identical object.

The aim of this paper is twofold: to consider in detail the objections against the existentialist view on the content of visual experience and to develop and defend a version of it that avoids these objections, solving, in particular, the so-called "particularity problem." I will argue that most objections to the existentialist view are objections only against its origi- 
nal formulation (McGinn and Davies) and against Searle's more elaborate causal version. The existentialist can avoid these objections by assuming that the existential content of visual experience takes the form of relativized content (rather than a classical proposition), modeled as a propositional function from the sextuple of object, agent, time, location, causal relation, and world to truth-values. In this sense, the content of experience corresponds to the content of a predicate rather than that of a complete sentence.

Against Soteriou's argument, I claim that the rejection of the existentialist view does not necessarily follow from the acceptance of Searle's socalled assumption that the question of veridicality of experience cannot be settled independently of the question of whether an object is being perceived and the rejection of Searle's causal version of the existentialist view. If the causal relation does not belong to the content of experience itself, it can be seen as belonging to the rich circumstances of evaluation against which the content is meant be evaluated.

Against Tye, I claim that the existentialist view can also solve the problem of particularity, albeit not in the original way suggested by Searle. Visual experience has a general content rather than an object-involving content. However, to count as the content of a visual experience that general content must be true of the particular object located in the perceiver's visual field at the time the mental state occurs that is causally responsible for that mental state in the actual world. Therefore, even though the object does not belong to the representational content itself, the experience is only satisfied by its presence and not by the presence of any other qualitatively identical object.

\section{The existentialist view}

Among the recent literature, the first to support the existentialist view was the work of McGinn (1982). According to him, the content of visual experience could not be specified by the employment of singular terms (like demonstratives), that is, "terms that refer to the object of experience" (1982, p. 51). An accurate description of the content of visual experience should employ only general terms (this is what McGinn 


\section{6}

calls the "generality thesis"). Therefore, the content of my visual experience, say, of a yellow cube straight ahead, represents the world as containing $a$ or some yellow cube straight ahead rather than this or that cube in particular. There are, or could be, many cubes in the world which equally "fit" the content of an experience of a yellow cube straight ahead; hence, the content of experience does not constitute or establish the relation to a particular perceptual object (1982, p. 50).

However, Davies was the first to explicitly state the existentialist view: If perceptual content is phenomenological content then, it seems, it is not object-involving. But from this it does not follow that perceptual content is not truth conditional-not fully representational; for we can take perceptual content to be existentially quantified content. A visual experience may present the world as containing an object of a certain size and shape, in a certain direction, at a certain distance from the subject. It matters not at all to that existentially quantified content of a subject's experience whether, for example, it is Fido or Fifi that she is looking at. (DAVIES, 1992, p. 26)

According to the existentialist view, the representational content of experience takes the canonical form of an existential, quantified proposition. My visual experience of a yellow cube straight ahead represents a yellow cube straight ahead rather than this or that yellow cube straight ahead. Assuming a Russellian view on the nature of propositions, the content of visual experience is property-involving, but not "object-involving." The objects of our visual experience are not constituents of the representational content of experience. In other words, the content of visual experience is best modeled as a general Russellian proposition rather than as a singular Russellian proposition.

The existentialist view has two motivations. First, if content of visual experience is phenomenological content, as Davies claims, and if the object and any other particular do not contribute to the phenomenology of experience, then visual experiences with the same phenomenal character can represent the world as being the same way, even if they are experiences of numerically different objects. Therefore, the content of experience is not to be specified by using singular terms, "on pain of denying that distinct objects can seem precisely the same" (McGINN, 
1982, p. 51). Now, under the Russellian view on the nature of propositions (as contents consisting of entities rather than of modes of presentation), the content of experience cannot be singular or object-involving.

Another reason in favor of the existentialist view is that experiences can represent the world as being the same way, even if one of them is a hallucination in which no object is perceived at all. Therefore, without the need to ascribe to the visual experience of different levels of content as concurrent views, the existentialist view can easily accommodate the intuitions (i) that hallucinatory experiences may have the same content of certain normal experiences (either veridical or illusory) and further (ii) that such content is in fact illusory (or neither veridical nor illusory). Both my visual experience and my hallucinatory experience of a yellow cube project the same accuracy conditions on the world, modeled as the existential proposition that there is a yellow cube straight ahead. They both represent the world exactly in the same way, viz., as containing $a$ yellow cube straight ahead. My experience is veridical when there is in fact a yellow cube straight ahead. It is illusory either when the cube straight ahead is not yellow or when the yellowish thing straight ahead in my visual field is not cubic. Further, it is hallucinatory when there is simply no object of the relevant sort in my visual field.

In the literature, the claim that that the content of visual experience and the objects of experience are mutually independent is further supported by an appeal to two well-known scenarios. There are cases in which we want to say that the content of experience is accurate even though the experience is illusory, and there are cases where we want to say that the content of experience is accurate even though the experience is hallucinatory. In both types of cases, the object represented in the content of experience is not the object perceived. Following the literature, let us call the first scenarios cases of veridical misperceptions (SOTERIOU, 2000) and the second scenarios cases of veridical hallucinations (LEWIS, 1980).

A simple case of misperception occurs when a subject perceives an object as having some property or properties that, in fact, it lacks. Now, adapting a scenario suggested by Soteriou as our example (2000, p. 180), let us suppose that, due to the fact that the perceiver is wearing displacing glasses, she perceives a yellow cube straight ahead of her which in fact 


\section{8}

is to her left. In this case, the subject misperceives the object, since her visual experience places the yellow cube in the incorrect location. Further, let's assume that there is in fact a second yellow cube straight ahead of the perceiver, and that it seems to the perceiver that this second yellow cube is located to her right where, in fact, there is a third qualitatively identical yellow cube that is too far to the right of the subject to be perceived. Under the assumption that the content of experience is best modeled as an existential proposition, the content of experience in this case seems to be accurate; after all, there is a yellow cube straight ahead as the experience represents it to be. Nevertheless, the experience itself is illusory since the yellow cube that is seen is not straight ahead of the perceiver, but to her right.

According to Soteriou, the case can be suitably amended, so that the perceiver may also misperceive other aspects of her environment even though the content of her experience remains accurate. Tye provided an interesting example of this:

Suppose that I am looking directly ahead and that, unknown to me, there is a mirror in front of me placed at a $45^{\circ}$ angle, and behind which there is a yellow cube. Off to the right of the mirror, and reflected in it, is a white cube. Through special lighting conditions, this cube appears yellow to me. $(2009$, p. 79$)$

Under the assumption that the content of my experience is best modeled as an existential quantified proposition, the content of experience in this case seems to be veridical; after all, the world appears to me as my visual experience represents it to be, since there is in fact a yellow cube straight ahead. Nonetheless, my visual experience is clearly illusory, since I do not see the yellow cube that is in fact straight ahead of me as my visual experience represents it to be, since that cube is behind the mirror outside my visual field. Rather, what I see is the image of another white cube reflected on the mirror placed at a $45^{\circ}$ angle, which appears to be yellow because of special lighting conditions. Thus, while my experience is illusory, the content of my experience is veridical or accurate. ${ }^{1}$

Scenarios of veridical hallucinations are also supposed to establish the claim that there can be cases where the content of experience is veridical - the world fully matches the content of experience - and yet no 
object is perceived. Let us suppose there is a yellow cube in front of me. However, unbeknownst to me, the information reflected in the light from the cube and reaching my retina is processed no further. An evil neuroscientist (or a Cartesian demon, if you will) has blocked the signals from my retina to my optic nerve, while simultaneously activating my visual cortex by means of electrical probes that work in the same way as neurological signals. Under these circumstances, I neither perceive nor misperceive the yellow cube for the simple reason that I do not see the yellow cube straight ahead of me in the first place. My experience is hallucinatory. Nonetheless, the content of my visual experience seems to be accurate; after all, there is a yellow cube straight ahead of me as my visual experience represents there to be.

Thus, our recognition of cases of veridical misperceptions and cases of veridical hallucinations is supposed to support the claim that content and object are mutually independent: we cannot deduce the content of an experience from knowledge of its object; and we cannot deduce the identity of the object of a visual experience from knowledge of its content (McGINN, 1982). The question of the veridicality of experience must be settled independently of the question of whether the object is perceived. The content of experience is veridical when there are particulars in the world that possess all of the properties specified by the content, irrespective of whether or not those particulars are experienced.

\section{Searle's conjunctive account}

As we saw, one of the reasons given in support of the existentialist view is the fact that the object does not contribute to the phenomenology of experience.Visual experiences may have the same phenomenal character, even if they are experiences of numerically different objects. According to Searle

But a problem immediately arises that we have not yet faced: we have discussed the case where a person sees that a yellow wagon is in front of him, but what about the case where he sees that a particular, previously identified, yellow station wagon is in front of him. When, for example, I see my own station wagon, the conditions of satisfaction require not 
merely that there be some station wagon or other satisfying my Intentional content, but rather that it be my very own. Now the question is; how does this particularity get into the Intentional content of the perception? Let us call this "the problem of particularity." (1983, p. 62)

Following Searle, let us suppose that there is the twin of our earth in a distant galaxy, one that is identical to our earth down to the last microparticle. Suppose further that, while on our earth Jones sees a yellow cube straight ahead, on the twin-earth, Jones' twin also sees a yellow cube straight ahead that is qualitatively identical to the yellow cube seen by Jones. The point is that the particular object to which the perceiver is perceptually related makes a constitutive difference to the representational content of visual experience. The accuracy condition of each perceiver's experience must be sensitive to which particular object is perceived. Jones's visual experience cannot be accurate only because there is in fact a yellow cube straight ahead of him. Rather, Jones's experience can only be accurate if the cube he is seeing straight ahead of him is yellow (and not any other qualitatively identical particular). If another qualitatively indistinguishable cube replaces the yellow cube straight ahead of Jones, then the accuracy conditions of Jones's visual experience change even if he cannot tell the two cubes apart. Therefore, there must be something wrong with the existentialist view.

To solve the problem of particularity, Searle has to make the existential content more elaborate. In his improvement of the existentialist view, the content of visual experience is specified by a conjunction. My visual experience of the yellow cube is veridical or accurate if (i) there is a yellow cube in my visual field, and if (ii) the fact that there is a yellow cube is causally responsible for my visual experience (1983, p. 123). In this view, veridical misperception and veridical hallucinations are in fact sheer cases of illusory experience, because there is no appropriate causal relation between the object and the mental state that represents it. If the yellow cube straight ahead is not causally responsible for my mental state representing a yellow cube straight ahead (either because the yellow cube straight ahead is behind the mirror and the cube I see is white in color, or because I am undergoing a hallucinatory experience), the representational content of my experience cannot possibly be veridical even if the world is as it appears to me to be. 
However, Searle's idea of making the causal self-referential condition part of the content of experience was rejected by numerous critics. A common complaint is that the idea is phenomenally inadequate. According to Tye, "the proposal (...) is not easy to swallow. Intuitively, when I see a tomato, for example, my visual experience is directed upon the tomato. It is not about itself in addition to the tomato" $(2009$, p. 80$)$. When we undergo the visual experience of a yellow cube straight ahead, it does not seem to us as if we are aware of the causal relation between the apparent object and our experience. According to Burge, the self-referentiality required by the conjunctive account is simply "too complex or too sophisticated" (BURGE, 1991, p. 198). It is cognitively too demanding to assume that every perceiver has the conceptual resources required to refer to her own token experience as caused by the fact it represents.

Under the assumption that the causal relation belongs to the representational content of experience and that the perceiver has knowledge of it, Searle's account of reference seems to be inherently descriptivist (BACH, 2007). If the causal relation belongs to the content of experience, the reference is determined satisfactionally rather than relationally (see BACH, 1987); in other words, the reference is not determined by the blind fact that the apparent object is causally responsible for the perceiver's experience, but rather by the perceiver's propositional knowledge of that fact. The reference of my experience to the yellow cube is not determined by the blind fact that the particular is causally responsible for my experience, but rather by my knowledge of that causal relation.

Therefore, under the assumption that the causal relation belongs to the content of experience and that the perceiver has knowledge of that relation, the conjunctive account cannot solve the particularity problem. In Searle's conjunctive account, the content of my visual experience of a yellow cube is not satisfied by that particular I am seeing, but rather by whatever particular satisfies the identifying condition of being the particular located in my visual field, which, at the time my mental state occurs, is causally responsible for that state.

However, against such charges, Searle insists that

[t]he agent need have no 'knowledge of the causal relation'. The causal feature is simply a feature of the content of the unreflective visual experience. (1991, p. 234) 
In defense of Searle's account, one might reasonably sustain that the causal self-referential component can be part of the content of the perceiver's experience even if the perceiver does not possess the causal, self-referential concepts required to provide a canonical specification of that content. To hold that the perceiver need have no knowledge of the causal relation is to hold that she represents the causal self-referential condition nonconceptually. However, I am inclined to side with Soteriou when he claims that "even if we accept that experience can have a non-conceptual content we still need to maintain that the content that we ascribe to a subject should serve some explanatory purpose" (2000, p. 182). Now, there are no discriminatory abilities left unexplained if one does not endorse Searle's conjunctive account by including the causal self-referential condition in the representational content of visual experience.

However, in his Intentionality, Searle further claims that the causal selfreferential condition could be part of the representational content of visual experience even if the perceiver does not see the causal relation:

Furthermore, when I say that the visual experience is causally selfreferential I do not mean that the causal relation is seen, much less that the visual experience is seen. Rather what is seen are objects and states of affairs (...). (1983, p. 49)

Intuitively, if we assume that we do not even see the causal relation, we have no reason to endorse Searle's claim that this relation is part of the content of experience, even under the assumption that such content is nonconceptual.

\section{Searle's assumption}

According to Tye, Searle's causal version of the existentialist view should be rejected because "it yields an unequivocal result" in certain cases in which such a result is not warranted $(2009$, p. 79$)$. These are the discussed cases of veridical misperceptions and veridical hallucinations. The causal version of the existentialist thesis cannot accommodate cases of veridical hallucinations because 
[a]ccording to that thesis, there can be no such thing as a veridical hallucination, since when an hallucination is present, there is no object of the relevant sort in the scene before the subject's causing his or her experience. Thus, every hallucination must be counted as falsidical. This obviously will not do. (2009, p. 2009, my emphasis)

The causal version of the existential thesis yields the unequivocal result that cases of veridical hallucinations must be counted as falsidical. The same criticism applies to cases of veridical misperceptions, since Searle's conjunctive account cannot allow the possibility of such a thing as a veridical misperception. Remember Tye's example of veridical misperception? If the yellow cube represented by my visual experience as being straight ahead is in fact behind the mirror and hence is not causally responsible for my visual experience of a yellow cube straight ahead - the cube causing my visual experience is white in color and only appears to me as yellow owing to the special lighting conditions of the environment - then the existential content must be counted as falsidical simpliciter. ${ }^{2}$

The underlying assumption of Searle's conjunctive account is that the question of whether the content of experience is veridical cannot be settled independently of the question of whether the represented object is the object perceived. Following Soteriou, we may call this Searle's assumption (2000, p. 176).

However, Searle's assumption is independent of Searle's conjunctive account of the content of experience. In other words, even if one is hostile to the idea of making the causal relation part of the content of experience, one may still have reasons to endorse Searle's assumption. According to Burge,

[i]t is not enough for the satisfaction of the intentional state that there be some entity in the vicinity that has the visible properties presented by experience (...). The intentional must itself somehow reflect the causal condition of its satisfaction. Searle emphasizes this point and is entirely right to do so. (1991, pp. 201-202)

As Soteriou remarks (2000, p. 177), Burge believes that we can discard Searle's idea that the causal relation belongs to the representational content of experience, yet retain Searle's assumption alone by intro- 


\section{4}

ducing a demonstrative element to the representational content of experience:

By including a demonstrative element in the content of visual experience $(. .$.$) one may reflect in the intentional content the$ condition that to be veridical the experience must be caused by an entity that is (say) F. An account of the semantic or intentional nature of the visual demonstrative should require that the demonstrative fails to apply to anything unless the experience is appropriately caused. (1991, p. 202)

In this way, the content of visual experience takes the predicative form "that F é G" (consisting of a demonstrative element "that F" and of an attributive element " $G$ ") rather than the existential form (an F that is $G$ ). According to Burge, when the visual experience is not appropriately caused, the demonstrative element "that F" fails to apply. Burge's suggestion applies nicely to simple cases of hallucination, such as cases of failed demonstrations. When the subject is experiencing hallucination, no object of the relevant sort in the scene before the subject is causally responsible for his or her hallucinatory experience, and hence the demonstrative element "that F" fails to apply. Nevertheless, in the same way that a failed demonstration still has a representational sort of content, insofar as it still has a character or linguistic meaning, as a failed demonstration, the hallucinatory experience still has representational content.

However, the suggestion cannot apply to cases of veridical misperceptions and veridical hallucinations. For one thing, if there is in fact a yellow cube straight ahead of me, regardless of whether or not I am really seeing it, I may successfully refer to it in the demonstrative way suggested by Burge: that cube straight ahead is yellow (that $F$ is $G$ ) and the content of my experience must count as accurate. Therefore, the demonstrative element "that cube" cannot replace the role of the causal relation - "the cube that is causally responsible for this visual experience" - in Searle's conjunctive account of the content of visual experience. The inclusion of a demonstrative element in the representational content of visual experience cannot explain why cases of veridical misperceptions and veridical hallucinations are falsidical simpliciter, as Searle's assumption requires. 
As Soteriou remarks, neither Burge nor Searle provide a supporting argument for Searle's assumption (2000, p. 178). Thus, the crucial question is whether we have an independent reason to assume that an experience cannot be veridical unless the object represented is the object perceived. Soteriou provides an argument in support of Searle's assumption. In a nutshell,

[i]f one allows the possibility of veridical misperception, then one must give up the following assumption: if some part of the subject's environment is different from the way it is represented to be, then at least one of the conditions required for the content of representation to be correct is not satisfied. (2000, p. 180; my emphasis)

However, unless we assume that the causal relation itself is represented by visual experience, strictly speaking, there is nothing in the subject's environment that "is different from the way it is represented to be" in case of veridical misperception. When I am undergoing the veridical misperception of a yellow cube straight ahead, my experience represents only the proposition that there is a yellow cube straight ahead and not the additional fact that the yellow cube straight ahead is causally responsible for my visual experience. Now if, as matter of fact, there is a yellow cube straight ahead, there is nothing in my environment different from the way it is represented by my visual experience.

Soteriou's insight is better captured by means of the Kaplanian notion of circumstance of evaluation. According to Kaplan, semantic content is true or false not only at worlds, but also relative to times, standards of precision, and locations - the so-called circumstance of evaluation. What goes into the circumstance of evaluation is determined by "the amount of information linked to the degree of specificity of contents, and thus to the kinds of operators in the language" (1989, p. 502). Natural languages contain modal, temporal, and, maybe, locational operators. For that reason, worlds and temporal and place-neutral contents are meant to be evaluated in terms of worlds, times, and locations.

In analogy with the operators of natural languages, we may think of perception or visual experience as a determining factor of the circumstances against which the content of experience is meant to be evaluated (we shall develop this idea in the following sections). In this sense, what 
goes into this circumstance of evaluation is determined by what counts as a perception or as a visual experience. For example, for a mental state representing the existential proposition that there is a yellow cube straight ahead to count as a visual experience, (i) there must be a yellow cube straight ahead, (ii) located in my egocentric visual field, (iii) at the time my mental state occurs, and (iv) causally responsible for that mental state in the appropriate way. If my mental state is caused by some event in the past, it must be counted as a memory or imagination rather than as a visual experience. Likewise, if that mental state is not caused in the appropriate way by the cube in my visual field, it cannot be counted as a visual experience of the cube.

Now, we have a better defense of Searle's assumption. To be sure, my mental state of a yellow cube straight ahead does not represent the further fact that the existence of the yellow cube straight ahead is causally responsible for that mental state. Moreover, there is nothing in the representational content itself that can replace or reflect the role that the causal relation plays in Searle's account (Burge's suggestion). Nevertheless, that causal relation must be seen as part of the rich circumstances against which that content is meant to be evaluated if that mental state is to be counted as a visual experience. Even though my visual experience represents only a yellow cube straight ahead, it can be accurate or veridical only if the fact that there is a yellow cube straight ahead is causally responsible for my mental state. Thus, the question as to whether the experience is veridical cannot be settled independently of the question of whether the represented object is the object perceived (Searle's assumption).

\section{Impure existential contents}

Now, the accuracy condition of visual experience is sensitive not only to the particular object to which the perceiver is perceptually related but also to several other parameters. To begin with, the accuracy condition of visual experience is sensitive to the time the experience or the mental states occur. Suppose that, at 2 p.m., there is a yellow cube straight ahead, whereas at 2:10 p.m. the cube is removed from my visual field. Suppose, in addition, that my visual experiences at 2 p.m. and at 2:10 p.m. equally 
represent the timeless existential proposition that there is a yellow cube straight ahead. Intuitively, if my first experience is accurate, my second visual experience is clearly falsidical. However, under the assumption that existential contents are timeless, we must say that the second content is also accurate; after all, if there is no yellow cube straight ahead now, there was one ten minutes earlier.

The natural way out is to incorporate the time the experience occurs into the existential content of visual experience. In the former case, my visual experience represents a yellow cube straight ahead at 2 p.m., whereas in the second case, it represents a yellow cube straight ahead at 2:10 p.m. Thus, by relating the time the mental state occurs to existential content, the content of the first experience turns out to be accurate, while that of the second experience turns out to be falsidical. Now, however, according to Tye, the existential content of visual experience is "no longer pure: it includes a particular time" (2009, p. 90).

The accuracy condition of visual experience is also sensitive to the location of the object (in the perceiver's egocentric visual field). Suppose now that there is a yellow cube straight ahead in Lithuania even though there is no yellow cube anywhere else. Intuitively, if I am in Lithuania and the yellow cube straight ahead is in my egocentric visual field, the existential content of my visual experience turns out to be accurate. However, if I am in Rio and the yellow cube straight ahead is not in my visual field, the existential content of my visual experience must be inaccurate. However, under the assumption that existential contents are localneutral, we must say that the second existential content is also accurate; after all, if there is no yellow cube straight ahead in my visual field, there is one in Lithuania.

The natural way out is to incorporate the location of the object into the existential content of visual experience. In the former case, what visual experience represents is that there is a yellow cube somewhere in Lithuania, whereas in the second case, visual experience represents a different existential content, namely, that there is a yellow cube straight ahead in Rio. Once more, the existential content of visual experience is no longer pure; rather, it is party singular.

Moreover, the accuracy condition of visual experience is also sensitive to the person undergoing the visual experience. Suppose now that there 


\section{8}

is a yellow cube straight ahead of someone else even though there is no yellow cube straight ahead of me. Intuitively, if I am the perceiver, the content of my experience is clearly falsidical. However, under the assumption that the existential content is person-neutral, that content turns out to be accurate too.

The natural way out is to incorporate the perceiver herself into the content of visual experience. What my visual experience represents is that there is a yellow cube straight ahead of me. Therefore, the content of my experience is unequivocally inaccurate. Nevertheless, the above difficulty recurs. The existential content of visual experience turns out to be impure or partly singular.

\section{The relativized content of experience}

However, to solve the particularity problem, the existentialist does not need to incorporate the location of the object, the time, or the perceiver into the content of experience (for the same reason, he neither needs to incorporate the object nor its causal relation into that content). According to a proposal inspired by Kaplan's idea that circumstances of evaluation are determined by operators of natural language, all we need to do is think of (i) the object, (ii) its location, (iii) the time, (iv) the perceiver, and (iv) the fact that the object is as causally responsible for the mental state as crucial parameters of the rich circumstance of evaluation determined by the fact that that mental state in question is a visual experience.

This proposal is based on Recanati's insightful assessment of Searle's account (RECANATI, 2007). Recanati's first step toward clarifying the content of visual experience is restating Searle's distinction between psychological mode and representational content. Searle emphasized the similarity between speech acts and mental states such as belief. Both have a dual structure: content and mode. The "psychological mode" corresponds, on the side of mental states, to the illocutionary force on the side of speech acts. To say "there is a yellow cube straight ahead" is to perform a speech act whose content is the proposition that there is a yellow cube straight ahead and whose force is that of an assertion. Likewise, to believe the sentence "there is a yellow cube straight ahead" is to be in a doxastic 
state whose content is the same as the proposition that there is a yellow cube straight ahead and whose psychological mode (propositional attitude) is that of belief.

Now, the same dual structure between psychological mode and content can be generalized. According to Searle, the same representational content can be entertained in various distinct psychological states. In Searle's account, psychological modes are the different specific relations a subject has to the same proposition, that is, the different specific ways that the same content is entertained that then turn the mental state into a specific kind of state. Thus, it is, for example, possible to see a yellow cube straight ahead, to desire a yellow cube straight ahead, and to think of a yellow cube straight ahead. In these various cases, the contents remain the same, whereas the psychological modes vary. In the first case, the psychological mode is that of a visual experience; in the second, it is that of a desire; and, in the third, it is that of a thought.

However, in opposition to beliefs, desires and illusory states, and hallucinations, visual experience (perception) like memory and knowledge is a factive attitude: one only perceives or sees that there is a yellow cube straight ahead if in fact there is a yellow cube straight ahead. In other words, for an experience of a yellow cube straight ahead to count as a visual experience or as a perception, there must be a yellow cube straight ahead. Thus, if psychological modes or propositional attitudes are relations of subjects to propositions, perception (visual experience) is a mental relation to true propositions.

Nevertheless, this is not enough. For a mental state representing the existential proposition that there is a yellow cube straight ahead to count as a visual experience, the existing yellow cube straight ahead represented by the mental state must be causally responsible for the mental state itself in the appropriate way. For this reason, the causal relation (self-referential condition) that figures in Searle's analysis is determined by the perceptual mode rather than by the content itself (RECANATI 2007, pp. 131-132). Thus, contrary to what the conjunctive account holds, the visual experience of a yellow cube represents only the proposition that there is a yellow cube straight ahead. The causal relation belongs to the circumstance against which that content is meant to be evaluated rather than to the content itself, if that mental state is to be counted as a visual experience. 
Now the same reasoning applies to the other parameters: (i) the location of the object, (ii) the time, and (iii) the perceiver herself. To begin with, for a mental state representing the proposition that there is a yellow cube straight ahead to count as a visual experience, it must be the case that the mental state in question is caused by something that occurs at the time that the mental state in question occurs. If the mental state represents the same proposition but is caused by some past event, it must count as a memory or as imagination rather than as a perception or visual experience. Thus, for a mental state representing at $2 \mathrm{p} . \mathrm{m}$. that there is a yellow cube straight ahead to count as a visual experience, it must be caused by something at 2 p.m. However, as before, the time itself is not represented, and thus, it is not part of the representational content itself. Rather, it belongs to the rich circumstances against which the content is meant to be evaluated.

Secondly, for a mental state representing a content to count as a visual experience, the object represented must be located in the perceiver's visual field. For a mental state representing that there is a yellow cube straight ahead to count as a visual experience, the yellow cube must be located in the perceiver's visual field. Intuitively, I cannot see a yellow cube straight ahead if the cube is in Lithuania and I am in Rio, but, as before, the fact that the object must be located in the perceiver's visual field is not part of the content itself. Rather, it is part of the rich circumstances against which that content is meant to be evaluated.

Thirdly and lastly, for a mental state representing the proposition that there is a yellow cube straight ahead to count as a visual experience, it must be the case that the mental state in question belongs to the very subject located at the center of the visual field (the perceiver). If the mental state represents that same proposition, but belongs to someone else outside the visual field, it cannot be counted as a visual experience. Nonetheless, as before, the perceiver's position is not part of the content itself. My visual experience represents a yellow cube straight ahead and not that there is a yellow cube straight ahead of me. If the psychological mode of that content is to count as visual experience, the perceiver is part of the rich circumstances against which that content is meant to be evaluated.

We can now summarize all conditions in the following terms: for a mental state representing the content that there is a yellow cube straight 
ahead to count as visual experience (i) there must be a yellow cube straight ahead, (ii) located in the perceiver's visual field, (iii) at the time the mental state occurs, and (iv) causally responsible for that mental state. All these parameters belong to the rich circumstances of evaluation rather than to the content itself.

Classical propositions are contents that have a truth-value relative only to a possible world. For example, the content of my utterance "there is a yellow cube straight ahead of Peter at 2 p.m." is true just in the case that there is a yellow cube straight ahead of Peter at $2 \mathrm{p} . \mathrm{m}$. in the actual world, and the content of my belief that "Peter is seeing a yellow cube straight ahead of him at 2 p.m." is true just in the case that Peter is seeing a yellow cube straight ahead of him at 2 p.m. in the actual world.

However, not all content takes the form of a classical proposition. Indeed, some relativistic contents possess a truth-value not only relative to a world, but also relative to a time, a person, and other parameters. Visual experience is the case in point. My experience represents that there is a yellow cube straight ahead. However, as we saw above, that proposition is incomplete in the light of the standard semantics. It is an object, agent, time, location, and world-neutral content that is true only relative to the rich circumstances of evaluation. Thus, the content of experience corresponds to the content of a predicate rather than to that of a complete sentence that is true only of the particular object located in the perceiver's visual field at the time the mental state occurs that is causally responsible for that mental state in the actual world - that is, the content of experience is a complex property that, in Lewis's jargon, the subject self-ascribes.

Therefore, such incomplete content is best modeled as a function from the sextuple of object, agent, time, location, causal relation, and world to truth-values. Thus, in the case of my visual experience of a yellow cube straight ahead, we have the following: when the object is the yellow cube, the time is the time at which my experience occurs; the location of the cube is in my visual field straight ahead of me (as the agent); the cube is causally responsible for my experience and the world is the actual world, the value of that functions is "the True", while anything otherwise is "the False".

However, in Recanati's moderate relativist framework, visual experience has a further layer of content; it also represents a classical propo- 


\section{2}

sition, what Recanati calls the Austinian proposition (2007, p. 6). The Austinian proposition is what we get when we incorporate all the parameters of the rich circumstances of evaluation into the representational content of experience. Thus if, on the one side, my visual experience of a yellow cube represents incomplete content, namely, a yellow cube straight ahead, on the other side, it also represents the classical proposition that there is a yellow cube in my visual field straight ahead of me at 2 p.m. causally responsible for my visual experience in the actual world. According to Recanati,

[a]nother line of defense is available to Searle. He may insist that it is part of the subject's perceptual experience that that experience is caused by its object. The 'causation' component is not external to the content of the experience, but an integral part of it. With this I agree - but I do not think Searle's position is thereby justified. The subject is aware of the perceptual nature of his experience: he knows he is perceiving rather than, say, expecting or imagining. So there is a sense in which the complete content of his experience is self-referential: but the 'complete content' of the experience involves more than the propositional content - it also involves the psychological mode, of which the subject is aware and which determines the additional, selfreferential condition. (2007, pp. 133-134)

Arguably, the suggestion that my visual experiences of a yellow cube straight ahead also represent the object located in my egocentric field, the time my mental state occurs, the fact that such an object is causally responsible for my mental state and the world is subject to the same criticism directed by Searle's account. First, it is cognitively too demanding to assume that simple creatures like small animals and infants are capable of knowing or of being aware that they are perceiving rather than expecting or imaging something.

The way out of this charge is to assume that the mental state representing the Austinian proposition is nonconceptual in the sense that the perceiver need not possess the causal, self-referential concepts required to provide a canonical specification of that Austinian proposition. Nevertheless, even if we accept that visual experience represents Austinian propositions nonconceptually, we still need to show that such content is 
somehow indispensable to account for behaviors that would otherwise be left unexplained (SOTERIOU, 2000, p. 182).

The only sort of behavior that could be accounted for by the nonconceptual Austinian contents is disagreement. Frege is famous for having argued that the object of agreement and disagreement are classical propositions. Suppose I say that there is a yellow cube straight ahead and you disagree. Now, if what we both represent is only the incomplete content that there is a yellow cube straight ahead, there is no possibility of a real disagreement between us unless we are in the same epistemic situation. The content of my visual experience is true of the yellow cube in my visual field straight ahead of me at the time my experience occurs and that is causally responsible for my experience. On the other hand, the content of your experience is true of the yellow cube that is in your visual field straight ahead of you at the time your experience occurs and that is causally responsible for your experience. By representing the relativistic incomplete content indicated, we can only disagree if we are in the same epistemic situation, which must be characterized as follows: there is something in our visual field straight ahead of each of us at the time our mental states occur that is causally responsible for our mental states. I believe that this thing is a yellow cube and you disagree. However, if what we represent is the relativistic incomplete content and, further, if we are not in the same epistemic situation, there can be no real disagreement between us, but only misunderstanding. I am talking about something that is true of my epistemic situation, and you are talking about something that is true of your epistemic situation. Or so the argument goes.

The ascription of complete Austinian contents serves the purpose of explaining the disagreement over contents of visual experience when the contenders are not in the same situation. If the contenders are not in the same epistemic situation, they can only disagree over an Austinian content (arising by the incorporation of the mentioned parameters into the relativistic incomplete content of experience). However, even if we accept Frege's assumption that only classical propositions cab be objects of agreement and disagreement, we can only disagree over the content of some visual experience when we speak, judge, or think about it. At the nonconceptual level of perceiving a yellow cube straight ahead, there is no sense to talk about agreement and disagreement. Thus, there is no 


\section{4}

point in assuming that perceivers represent Austinian propositions in addition to relativistic incomplete contents.

A second reason to reject Recanati's moderate relativism arises if one accepts one of the most popular theories of the phenomenal character in philosophy of the mind today, namely, intentionalism. According to this view, either the phenomenal character of experience supervenes the representational content of that experience (weak intentionalism), or the two are identical (strong intentionalism). Thus, (i) assuming that the representational content of visual experience determines the phenomenal character of that experience (intentionalism), and further, (ii) that visual experiences, imagination, and episodic memories represent different classical propositions, one cannot accommodate the intuition that at least some visual experiences, imaginations, and memories have the same phenomenal character.

Intuitively, though, some episodic memories, imaginations, and visual experiences of a yellow cube straight ahead have the same phenomenal character (what can be accounted for in terms of the fact that they represent an incomplete existential content, viz., the property of being a yellow cube straight ahead). However, that could not be the case if, under the intentionalist assumption, the phenomenal character of visual experience is determined by a further layer of content representing a classical proposition resulting from the incorporation of the parameters of the circumstances of evaluation into the incomplete content.

\section{Solving the problems}

Soteriou summarizes his argument against the generality thesis (the existentialist view) as follows:

(i) Those who accept an intentional account of experience should say that when s subject misperceived the world, the subject is having an experience with an intentional content that is non-veridical.

(ii) If one rejects Searle's assumption that the question of the veridicality of an experience cannot be settled independently of the question of whether an object is being perceived, one allows for the possibility of veridical misperception. 
(iii) Given (i) and (ii), the intentionalist should accept Searle's assumption.

(iv) If one accepts Searle's assumption and also accepts the generality thesis, then one will have to accept that all visual experiences represent a causal relation between an object and the experience itself.

(v) Searle's account of the content of experience should be rejected. Therefore,

(vi) The intentionalist should reject the generality thesis. (2000, p. 184)

The crucial premise in Soteriou's argument is the conditional (iv), according to which if one accepts Searle's assumption and the generality thesis (existentialist view), one has to accept the controversial further assumption that the causal relation is represented by visual experience (an assumption that must be rejected).

However, as we saw, we do not need to accept Searle's entire set of ideas in order to accept Searle's assumption. We may accept that the question of the veridicality of an experience cannot be settled independently of the question of whether an object is being perceived (not allowing for the possibility of veridical misperception), and we may also accept the generality thesis that the content of experience is existential (not specified using singular terms as demonstratives) without having to assume that the causal relation is always represented by visual experience. All we need to evade Soteriou's argument is to assume that the content of experience takes the form of relativized content, neither veridical nor falsidical per se, formally modeled as a function from the sextuple of object, agent, time, location, causal relation, and world to truth-values. In this way, the causal relation belongs to the circumstance of evaluation of that content rather than to the content itself.

Now, we also have a natural solution to the particularity problem. My visual experience represents only the existential proposition that there is a yellow cube straight ahead. Even though (i) the object, (ii) its location in my visual field, (iii) the time my experience occurs, (iv) myself as the agent, (v) the fact that such an object is causally responsible for my mental state, and (vi) the world does not belong to the content itself, the accuracy condition of my experience is sensitive to all these parameters. As a function from the sextuple of object, agent, time, location, causal 


\section{6}

relation, and world to truth-values, the value of that function is True only when the object is the yellow cube, the time is the time my experience occurs, the location of the cube in my visual field is straight ahead of me, and the cube is causally responsible for my experience and the world is the actual world. In other words, to count as a visual experience, that representational content can only be true if the particular object, which, being in my visual field, is straight ahead of me at the time my mental state occurs, is causally responsible for my mental state.

To the extent that neither the perceiver nor the time her experience occurs, nor the location of the object in my visual field, nor the causal relation, nor the world belong to the content, the content is purely general rather than partly singular. Moreover, the proposed reference of visual experience to particular objects is not mediated any more by the perceiver's knowledge that the particular satisfies the identifying condition of being located in the perceiver's egocentric visual field at the time the mental state occurs and being causally responsible for the mental state. Here, the reference is de re - that is, determined relationally by the blind fact that the object satisfies that identifying condition - rather than de dicto - that is, determined satisfactionally by the perceiver's knowledge that the particular object satisfies that condition. Consequently, what determines the reference of my mental state to the yellow cube is not $m y$ knowledge that the object causes my visual experience, but rather the blind fact that the object causes my visual experience.

The proposal also explains away the cases of veridical misperceptions and veridical hallucinations. According to Searle's assumption, those cases are cases of sheer illusory experiences. If a mental state represents a yellow cube straight ahead, but that yellow cube is not in the perceiver's visual field at the time the mental state occurs and is not causally responsible for that mental state, that state cannot count as a visual experience even if there happens to be a yellow cube straight ahead of the perceiver. As we saw, for a mental state whose relativized content is the property of being a yellow cube straight ahead to count as a visual experience, it must be caused appropriately by the object that, in the visual field, is straight ahead of the perceiver at the time and place her mental state occurs.

Now, the existentialist view must contest a final objection. According to Tye, 
[a] third difficulty is that if deviant causal chain counter-examples are to be avoided, it will have to be stipulated that the relevant causal chain is not deviant. But the conditions needed to spell out non-deviance are surely not ones that are perceptually available. $(2009$, p.80)

All we need to avoid the deviant causal chain is to appeal to Fodor's asymmetric dependence thesis. Cases in which there is a deviant causal chain between the visual experience and what it represents are ontologically dependent on the cases where there is a normal, non-deviant causal chain, but not the other way around. In other words, there is an asymmetry of dependence between the normal cases in which my visual experience is caused by the yellow cube in my visual field straight ahead of me and the deviant cases in which the same experience type is cause by something else. The first can subsist independently of the second, but the second can occur only because of the existence of the first. Now, nothing of this must be "perceptually available," because these parameters belong to the rich circumstances of evaluation rather than to the content itself.

${ }^{1}$ Interestingly, Tye offers a quite different reading of his own example. According to him, in light of the existentialist view, this visual experience is a veridical or accurate simpliciter. The existentialist account must be rejected, because "it yields an unequivocal result of veridicality in certain cases (like this) in which such a result is not warranted" (2009, p. 79-80).

However, only Searle's causal version of the existentialist view yields an unequivocal result in this case. Nevertheless, in Searle's causal account, this experience is not an accurate simpliciter, but rather an inaccurate simpliciter. We will return to this point in the following sections.

2 Tye's own singular thesis (when fulfilled) faces the same fate. It also results in unequivocal inaccuracy in cases of veridical misperception. In the singular view, both the cube I am seeing and the color property it appears to have are components of a singular, object-involving proposition represented by my visual experience. Thus, according to the singular thesis, my visual experience is inaccurate simpliciter, since the cube I see enters into the singular content of my experience, but it is white rather than yellow. According to Tye, though, "This does not seem the right thing to say. After all, it certainly appears to me that there is a yellow cube in front of me; and there is such a cube. The world is as it appears in this respect" $(2009$, p. 83).

doispontos, Curitiba, São Carlos, vol. 9, n. 2, p.63-88, outubro, 2012 


\section{References}

BACH, K. 1987. Thought and Reference. Oxford: Oxford University Press.

BACH, K. 1997. Searle against the World. Unpublished. URL:

$<$ http://userwww.sfsu.edu/ kbach/Searle.html>.

BURGE, T. 1991.Vision and Intentional Content. In: LEPORE, E;

GULICK, R. John Searle and His Critics. Oxford: Basil Blackwell.

DAVIES, M. 1992. Perceptual Content and Local Supervenience.

Proceedings of the Aristotelian Society 92, 1992.

KAPLAN, D. 1989. Demonstratives. In: ALMOG, J; PERRY, J;

WETTSTEIN, H. Themes from Kaplan. New York: OUP.

LEWIS, D. 1980. Veridical Hallucination and Prosthetic Vision.

Australasian Journal of Philosophy 58, 239-49.

McDOWELL, J. 1991. Intentionality De Re. In: LEPORE, E;

GULICK, R. John Searle and His Critics. Oxford: Basil Blackwell.

McGINN, C. 1982. The Character of Mind. Oxford: Oxford University Press.

MILLAR, A. 1991. Reasons and Experiences. Oxford: Clarendon Press.

RECANATI. F. 2007. Perspectival Thought: A Plea for (Moderate)

Relativism. Oxford University Press.

SEARLE, J. 1983. Intentionality. Oxford: Clarendon Press.

RESPONSE: REFERENCE AND INTENTIONALITY. In:

LEPORE, E; GULICK, R. John Searle and His Critics. Oxford: Basil Blackwell, 1991.

SOTERIOU, M. 2000. The Particularity of Visual Perception. European Journal of Philosophy 8, 173-189.

TYE, M. 2009. Consciousness Revisited: Materialism without Phenomenal Concepts. Cambridge: MIT Press. 